\title{
Paced Atrial And Ventricular Rhythm
}

National Cancer Institute

\section{Source}

National Cancer Institute. Paced Atrial And Ventricular Rhythm. NCI Thesaurus. Code C92232.

An electrocardiographic finding in which both the atrial and ventricular rhythm are controlled by an electrical impulse from an artificial cardiac pacemaker. (CDISC) 